\title{
Multiple Cutaneous Metastasis of Follicular Thyroid Carcinoma in the Scalp and Upper Extremities
}

\author{
Sibel Yıldırım (1), Zahide Çiler Büyükatalay (D), Gürsel Dursun (1) \\ Department of Otorhinolaryngologic Diseases, Ankara University School of Medicine, Ankara, Turkey \\ Cite this article as: Yıldırım S, Çiler Büyükatalay Z, Dursun G. Multiple Cutaneous Metastasis of Follicular Thyroid Carcinoma in the Scalp and \\ Upper Extremities. JAREM 2019; 9(1): 55-7.
}

\begin{abstract}
Cutaneous metastasis of differentiated thyroid carcinoma is rare, and it usually indicates advanced tumor stages. Most of these metastases are seen in the scalp. Lesions can be solitary or multiple. The metastatic deposits are typically present as slow-growing, erythematous or purple-colored, puffy, and ulcerated masses. In this case report, an aggressive follicular thyroid carcinoma with diffuse skin metastases has been discussed with a literature review.
\end{abstract}

Keywords: Cutaneous metastasis, follicular thyroid carcinoma, scalp metastasis

\section{INTRODUCTION}

Thyroid carcinoma is the most frequently observed endocrinal malignity. Differential thyroid carcinoma metastasizes to cervical lymph nodes via lymphogenic diffusion/emission, and rarely, hematogenic metastasis is observed. The presence of metastases during diagnosis is a bad prognostic sign. The most frequent distant metastases occur in the lungs and bone (1). Skin metastases are rare and are mostly indicative of an advanced stage tumor. The average survival following skin metastasis has been reported as 19 months (2).

The tendency of follicular thyroid carcinoma to metastase to the skin is greater compared to papillary, medullary, and anaplastic thyroid carcinomas (3). Skin metastases frequently settle at the scalp, face, or neck. Lesions can be single or multiple. They are typically slow-growing, erythematous or purple colored, puffy, and usually non-ulcerated masses (4).

This case report aims to discuss the clinical features and progress of a patient diagnosed with rarely reported follicular thyroid carcinoma that proceeded aggressively with dispersed skin metastases, other than clinical progress expected in differential thyroid carcinomas.

\section{CASE PRESENTATION}

A 58-year-old female patient presented with solid mass lesions on the head and shoulder that occasionally bled. This patient who had thyroidectomy 7 years before based on the multinodular goiter diagnosis had follicular thyroid carcinoma detected via histopathologic investigation and radioactive iodine history.
Scanning on the 6th day following operation when $150 \mathrm{mCi}$ l-131 was used, metastases spread to lungs were detected (Figure 1). Then, a high dose of I-131 (200 mCi) was applied, followed by a total of $1150 \mathrm{mCi}$ of additional I-131 as a result of high thyroglobuline during follow-ups. In the 6th year following diagnosis, 3000 cGy radiotherapy was applied after the detection of bone metastasis located in the 12th vertebrae during bone scintigraphy.

Approximately 6 years after the follicular thyroid carcinoma diagnosis, a physical examination of the patient revealed ulcersurfaced, hemorrhagic, purple colored giant mass lesions on the right scapula approximately $13 \times 13 \times 7 \mathrm{~cm}$ in size on the skin surface, multiple on the scalp with a maximum $5 \times 4 \times 15 \mathrm{~cm}$ in size and left shoulder with $7 \times 6 \times 3 \mathrm{~cm}$ size (Figure 2). The cytological examination of the skin lesion from the right shoulder of the patient obtained via a fine-needle aspiration biopsy was evaluated as compatible with follicular thyroid carcinoma metastasis. During the follow-ups, the recurrent mass which narrowed the air stream of the right thyroid lojor on the neck was observed, and tracheostomy was performed. Mass lesions suggestive of metastasis were observed in the right nasal cavity and right bulbus oculi (Figure 3). A surgical resection was not planned for these lesions since effective curative therapy would not be obtained due to widespread metastases and the masses being too large to be closed with primary repair.

The patient was sent to the medical oncology clinic for chemotherapy planning. After the detection of progression during doxorubicin therapy, nexavar therapy was initiated with indication-free drug application. Progression was observed during fol- 


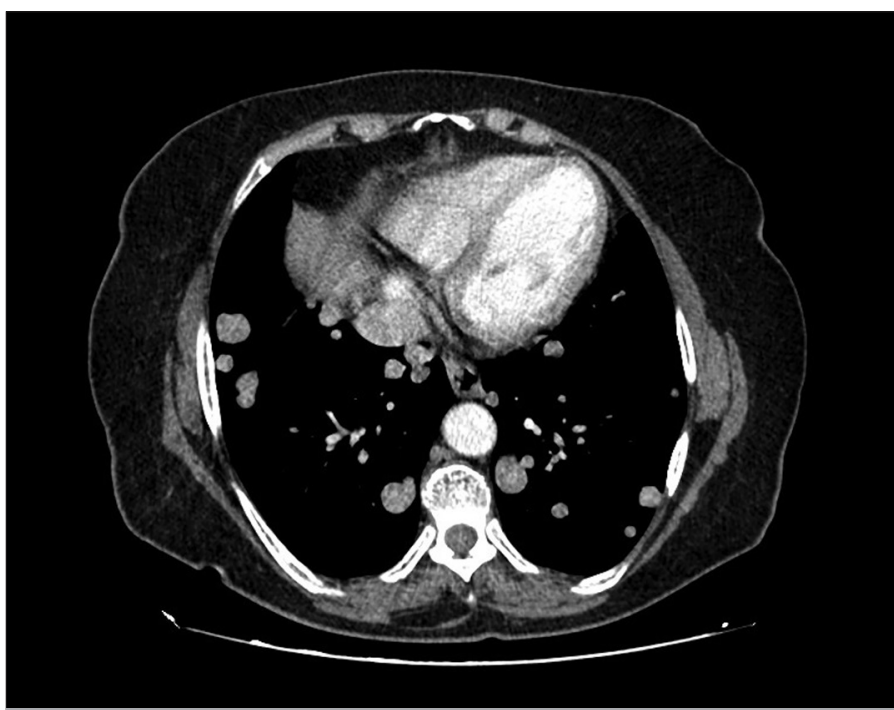

Figure 1. Multiple metastatic nodules in both the lungs detected by thoracic tomography

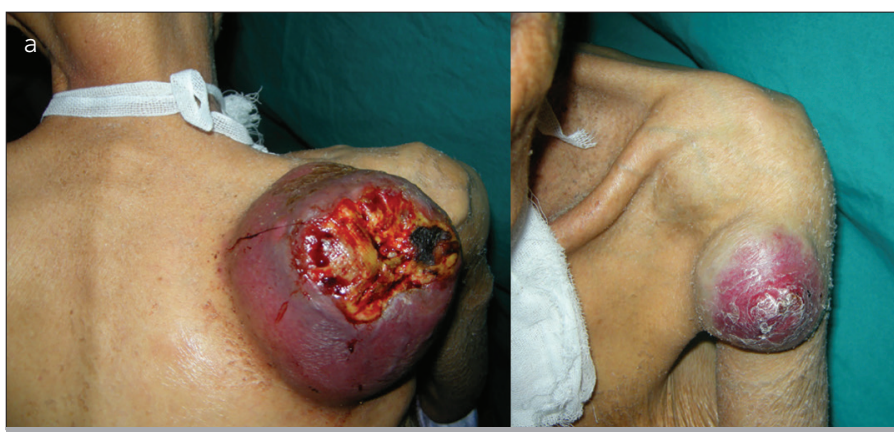

Figure 2a. Giant metastatic masses observed in the upper extremity

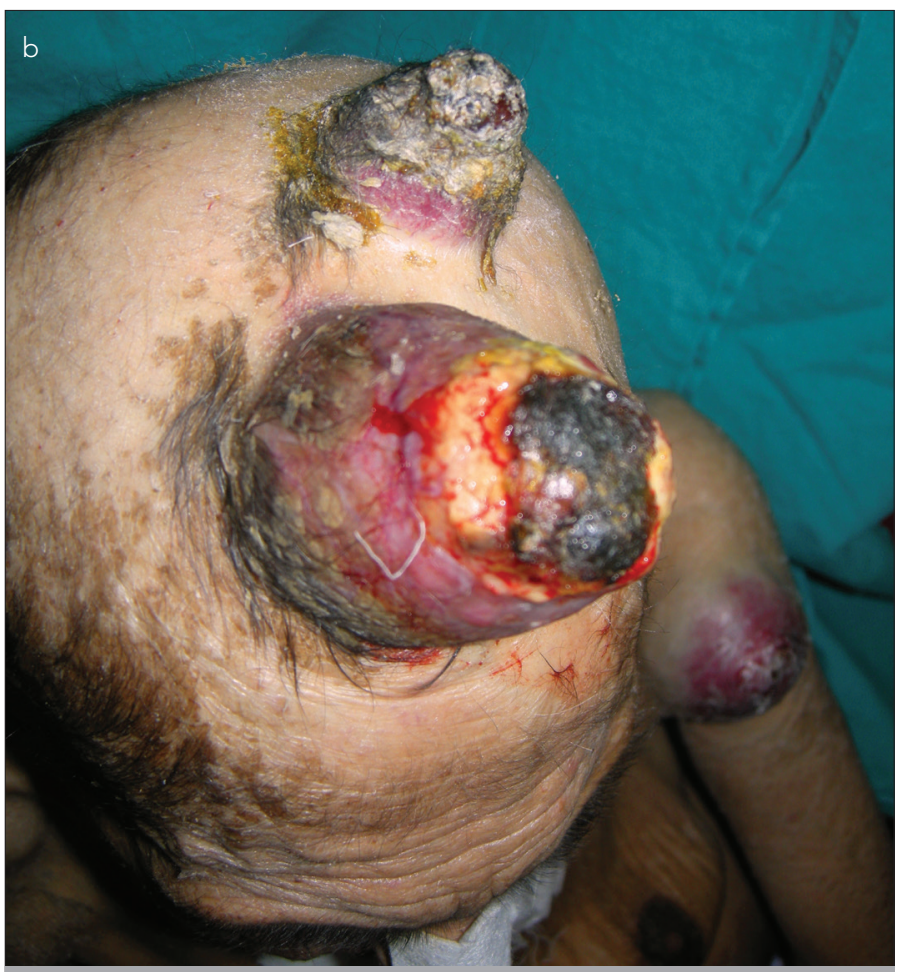

Figure 2b. Giant metastatic masses observed in the scalp

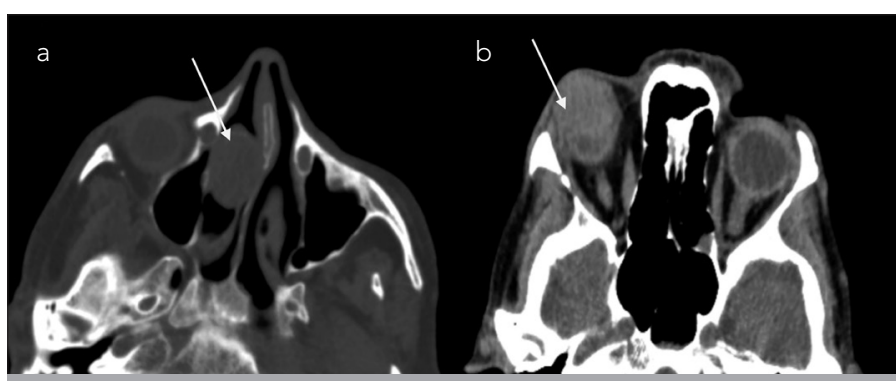

Figure $3 a, b$. Metastatic soft tissue appearance in the right nasal cavity (a) and soft tissue in the right bulbus oculi (b) detected by the axial section paranasal sinus tomography

low-ups, and the patient was resistant to nexavar therapy as well. She was exitus at the terminal stage while under palliative care.

Consent was taken regarding sharing of this information.

\section{DISCUSSION}

Skin metastases of visceral tumors are responsible for $2 \%$ of all skin tumors and in relation with breast, lung, colorectal, ovary, head and neck carcinomas, and renal and gastrointestinal system tumors (5). Skin metastasis is often a marker of an advanced stage disease with a bad prognosis (6). A limited number of thyroid carcinomas with skin metastases have been reported. Hoie et al. (7) investigated the presence of distant metastases in a papillary thyroid carcinoma series of 731 patients and detected distant metastases in 91 cases. Among these, only in 6 patients, skin metastasis was observed with a ratio of less than $1 \%$. In a second large series of 1800 patients, distant metastasis was detected in 100 patients; only in 1 patient, skin metastasis was observed with a ratio of $0.006 \%$ (8). Dahl et al. (2) presented 6 thyroid carcinoma cases with skin metastasis, and they found 33 more patients with skin metastasis during literature search. According to this study, skin metastasis was most frequently observed in papillary thyroid carcinoma (41\%). It is followed by follicular (28\%), anaplastic $(15 \%)$, and medullary $(15 \%)$ thyroid carcinomas. Meanwhile, Koller et al. (3) showed that follicular thyroid carcinoma had a greater tendency (42\%) to cause skin metastasis.

When follicular thyroid carcinoma metastases to the skin, the most frequently affected region is the scalp. The face, neck, chest, arm, and pelvic involvement are other skin regions (6). In the literature, 19 patients with follicular thyroid carcinoma and scalp metastases have been presented $(6,9)$. In the review by Quinn et al. (10), 9 out of 14 patients with skin metastases had also scalp metastases. In most of the cases reported in the literature, metastasis occurs after the diagnosis and treatment of the primary tumor, but in several cases, skin metastasis was initially indicative of the differential thyroid carcinoma $(4,11)$. The time between the diagnosis of thyroid tumor and the progression of skin metastasis is 1-18 years (6). In our patient, scalp metastasis occurred 6 years after the diagnosis.

In the literature, the presence of distant metastases was reported in most of the cases with skin metastases. Isolated scalp or other skin regions metastases are rarely observed (12). Metastases affecting multiple regions such as the lung, bone, nasal cavity, and eyes were also detected in our patient. 
Prognosis in widespread invasive follicular thyroid carcinomas worsens dramatically compared to differentiated thyroid carcinomas. The 5-year survival rate and mortality were reported as reaching up to $38 \%$ and $50 \%$, respectively (13). In our patient, widespread invasive follicular thyroid carcinoma was present, distant metastases were detected shortly after diagnosis, and the disease progressed rapidly with multiple organ involvement. The skin metastasis size increased rapidly, and the survival was 23 months after skin metastasis. The average survival rate was reported as 19 months in the literature (2).

\section{CONCLUSION}

Although skin metastases in thyroid carcinoma have rarely been reported in the literature, the presence of new lesions in a patient with a history thyroid carcinoma creates doubt in terms of metastasis. Clinically, while skin lesions located especially in the scalp region are investigated, the possibility of metastatic thyroid carcinoma should not be neglected.

In this case report, clinical features of skin metastasis in the invasive form of a patient with follicular thyroid carcinoma was compared to cases reported in the literature. The aim was to increase the knowledge and awareness of the fact that we can confront skin lesions and recurrence with clinical findings in patients with a history of thyroid carcinoma.

Informed Consent: Writen informed consent was obtained from the patient who participated in this study.

Peer-review: Externally peer-reviewed.

Author Contributions: Concept - S.Y., Z.Ç.B., G.D.; Design - S.Y., Z.Ç.B.; Supervision - Z.Ç.B., G.D.; Resources - S.Y., Z.Ç.B.; Data Collection and/or Processing - S.Y., Z.Ç.B., G.D.; Analysis and/or Interpretation - S.Y., Z.Ç.B.; Literature Search - S.Y., Z.Ç.B.; Writing Manuscript - S.Y., Z.Ç.B., G.D.; Critical Review - Z.Ç.B., G.D.

Conflict of Interest: The authors have no conflict of interest to declare.

Financial Disclosure: The authors declared that this study has received no financial support.

\section{REFERENCES}

1. Sugino K, Ito K, Nagahama M, Kitagawa W, Shibuya H, Ohkuwa K, et al. Prognosis and prognostic factors for distant metastases and tu- mor mortality in follicular thyroid carcinoma. Thyroid 2011; 21: 751-7. [CrossRef]

2. Dahl PR, Brodland DG, Goellner JR, Hay LD. Thyroid carcinoma metastatic to the skin: a cutaneous manifestation of a widely disseminated malignancy. J Am Acad Dermatol 1997; 36: 531-7. [CrossRef]

3. Koller EA, Tourtelot JB, Pak HS, Cobb MW, Moad JC, Flynn EA. Papillary and follicular tyroid carcinoma metastatic to the skin:a case report and review of the literature. Thyroid 1998; 8: 1045-50. [CrossRef]

4. Mukherjee T, Dutta R, Chandran V, Bawa R, Mohan C. Scalp Metastases from Thyroid Carcinoma. Med J Armed Forces India 2009; 65: 368-9. [CrossRef]

5. Somoza AD, Bui H, Samaan S, Dhanda-Patil R, Mutasim DF. Cutaneous metastasis as the presenting sign of papillary thyroid carcinoma. J Cutan Pathol 2013; 40: 274-8. [CrossRef]

6. Arslan S, Arslan E. Scalp metastases from thyroid carcinomas: review of clinical and pathological features. J Med Updates 2014; 4: 71-6. [CrossRef]

7. Hoie J, Stenwig AE, Kullmann G, Lindegaard M. Distant metastases in papillary thyroid cancer. A review of 91 patients. Cancer 1988; 61: 1. [CrossRef]

8. Dinneen SF, Valimaki MJ, Bergstralh EJ, Goellner JR, Gorman CA, Hay ID. Distant metastases in papillary thyroid carcinoma: 100 cases observed at one institution during 5 decades. J Clin Endocrinol Metab 1995; 80: 2041-5. [CrossRef]

9. Kumar M, Singh A, Mishra S. Scalp metastasis from follicular thyroid carcinoma diagnosed by fine needle aspiration cytology: A case series. Thyroid Res Pract 2016; 13: 80-2. [CrossRef]

10. Quinn TR, Duncan LM, Zembowicz A, Faquin WC. Cutaneous metastases of follicular thyroid carcinoma. Am J Dermatopathol 2005; 27 : 306-12. [CrossRef]

11. Lissak B, Vannetzel JM, Gallouedec N, Berrod JI, Rieu M. Solitary skin metastasis as the presenting feature of differentiated thyroid microcarcinoma: Report of two cases. J Endocrinol Invest 1995; 18 : 813-6. [CrossRef]

12. Sager S, Yilmaz S, Doner RK, Niyazoglu M, Halac M, Kanmaz B. A rare case of solitary subcutaneus scalp metastasis from follicular thyroid carcinoma revealed with positron emission tomography/ computed tomography:a case report and review. J Cancer Res Ther 2014; 10: 431-3. [CrossRef]

13. D'Avanzo A, Treseler P, Ituarte PH, Wong M, Streja L, Greenspan FS, et al. Follicular thyroid carcinoma: histology and prognosis. Cancer 2004; 100: 1123-9. [CrossRef] 